\title{
The Characteristics of Chinese and Westerners-From the Comparison of Tea and Coffee Culture
}

\author{
Ming Cai \\ Xinyang Agriculture and Forestry University \\ School of Foreign Languages, Xinyang Agriculture and Forestry University, Xinyang, China \\ 329495213@qq.com
}

Keywords: Tea Culture, Coffee Culture, Characteristics, Comparison

Abstract: This paper consists of five parts. The first part is introduction. The second part pays attention to the characteristics of Chinese tea culture and Western coffee culture. The third part mainly analyzes the comparison between tea culture and coffee culture, which gives the reader a clear glance. The fourth part gives an analysis of differences in character between Chinese and Western people. Finally, this thesis aims at making people understand Chinese tea culture and Western coffee culture clearly.

\section{Introduction}

As we all know, tea and coffee have become more and more popular as the world's two major drinks. When drinking tea, people would be immersed in the atmosphere of clearness, refreshment, idleness; people would lose themselves in a romantic situation while drinking coffee. China is the birthplace of tea culture and tea plays an important role in daily life. There are seven critical things in Chinese people's life: firewood, rice, cooking oil, salt, sauce, vinegar and tea. Similarly, the importance of coffee to the French (and France is a romantic country in the West so that this thesis takes France as an example) is like tea to Chinese. Coffee has become a necessity in France, for example, at breakfast, delicious croissant with a cup of sweet coffee will make you feel comfortable; at noon break, a cup of coffee in spare time can help you refresh yourself to work harder; after dinner, drinking a cup of coffee is helpful for your health. (Zheng Wanchun, 2006, p.22) ${ }^{[3]}$

Based on two cultures, this thesis aims at promoting the communication between two countries. Making more people understand the tea culture and coffee culture is not only to accelerate the progress of diet culture, but also to advance the health culture. In this thesis, special emphasis is put on the characteristics of tea culture and coffee culture, the relationship between tea and coffee and their own national historical culture, the spirit of tea culture and coffee culture in religion.

To help people know more about tea culture and coffee culture, we will make a comparison from the following aspects. 


\section{The Characteristics of Tea Culture and Coffee Culture}

This part tells the characteristics of Chinese tea culture from three aspects and the general characteristics of western culture by taking French coffee, American coffee and Italian coffee for example.

\subsection{The Characteristics of Chinese Tea Culture}

Chinese tea produces the profound influence in the history. Both the creation of tea culture and its continuity are lasting. In Dictionary of Chinese Tea, tea culture is: "the combination of material and spiritual wealth of tea which are produced in the process of human development. It makes material as its carrier and reflects spirit. It is a high harmonious product of material and spiritual civilization; it belongs to the "intermediary culture". Tea culture includes the history of tea, the cultural environment of the tea-producing areas, tea-producing technology, various kinds of tea and tea sets, tea-drinking custom, tea arts, books, paintings, poems about tea, and other cultural art forms. The structure of tea culture includes three levels which are material culture, institutional culture and spiritual culture.” (Chen Zongmao, 2008, p.12) ${ }^{[1]}$

Chinese tea culture is regional, diverse, common and open, which can be shown in the following aspects:

(1) Unity of Confucianism, Buddhism and Taoism. Chinese tea culture is created by the Confucianism, Buddhism and Taoism; it also integrates the basic principles of Confucianism, Buddhism and Taoism. Tea can make people feel fresh natural and pause. To some extent, it can help people get rid of physical and mental distractions, which is consistent with the Chinese concept of "quiet, tranquil" philosophy. In addition, it is also consistent with the intention of "Introspection practice" which is pursued by Confucianism, Buddhism and Taoism. Professor Wang Ling, the researcher of Chinese Academy of Social Sciences, believes that the spirit of Chinese tea culture is supported by the beliefs of the Taoism which is "the unity of the nature and human". Guided by the harmonious thinking from Confucian doctrine and proposed by the spirits of "saving the world" from Buddhism. Chinese tea culture is a cultural system which concentrated on the essence of Chinese traditional thought.

(2) The unity of material and spirit. Tea culture is an intermediary culture which perfectly combined material culture with spiritual culture. Tea's shape is extremely colorful, which depends on its enormous naming system, special flavor, color and fragrance. Tea formed an extremely rich products culture. Tea not only possesses the cultural color in material but also has content in spirit. People show their respect to the other though tea which is a symbol of spiritual civilization.

(3) The unity of utility and entertainment. The functions of tea culture determine its utility. Tea is an economic crop which is widely consumed. Drinking tea can quench thirst, build character, tea can also be used as medicines. There are many folk customs and tea party or tea worship, so tea culture showed a strong utilitarian. Tea culture is also a kind of cheer culture, people can have tea to amuse themselves, watch the tea ceremony, these present both utility and entertainment. The Tea Culture Festival activities rising in recent years reflect not only the utility based on economy, but also the entertainment.

\subsection{The Characteristics of Western Coffee Culture}

General characteristics of Western coffee culture are passionate, unrestrained free, simple and convenient.

Romantic French cafe culture symbolizes elegant charm, romantic ambience, and the 
pleasant. Coffee for them is not just a kind of drink; it implies a rich cultural meaning. The cafes covered all the urban and rural areas which represent their life style. The French do not pay attention to the taste, but the environment and mood which they are willing to spend a much higher prize for a small cup of coffee instead of buying a pot of coffee in the busy market. They sip it slowly, read books and news papers, and talk here and there even for a whole day.

People can enjoy coffee in America anywhere and anytime. When Americans drink coffee, it seems that they are engaged in a game without rules. They never pay much attention to the aspects of brewing coffee in Europe. Americans drink coffee in a free way and it is an important part of their lives. Americans are almost a day with coffee. In general, American life is a little busy and stressful, so they often prepare a large pot of electric filter coffee, and drink coffee from morning to evening. (Zell Doug, 2001, p.6) ${ }^{[10]}$

The characteristic of Italian coffee is quick which is reflected in its English name "quick", it needs less than 10 seconds for making and faster in drinking for it is just two or three sips. Generally speaking, when they get up, the first thing they want to do is to boil a cup of coffee. They like to drink coffee from drawn to dusk for men and women, old and young.

\section{A Comparison Between Tea Culture and Coffee Culture}

This part will make a comparison between tea culture and coffee culture from their drinking environment, their own historical culture and their relationship with the religion.

\subsection{Drinking Environment}

Tea drinking emphasizes environment very much, since the Chinese look on tea drinking as a kind of art. Today, the places such as modern teashops and teahouses are mostly for people to gather and drink tea together, with a friendly and passionate atmosphere; however, what the traditional Chinese tea art emphasized was the secluded, quiet and elegant atmosphere. The Monk Jiao ran of the Tang dynasty held the opinion that tea tasting was a noble and graceful activity and should be combined with enjoying flower, reciting poetries and listening to the music etc.

In fact, besides the scene and objects, tea drinking environment also emphasizes moral character of the drinkers. The tea feasts in Hanlin Academy, although there was much etiquette, didn't lack elegance; in the gathering of the men of letter, with beautiful and artistic scenes and together with graceful and elegant scholars, naturally it was of special appeal; the Chan Buddhism and Buddhist ceremonies needed quiet, and naturally kept far away from elegance and refinement. While in the teahouses and tea stands, there was usually an atmosphere of gaiety; drinking at home together with wife and children, there was the warmth of affection in the tea. Therefore, the tea drinking environment emphasized the harmony of tea, drinkers, scene and objects; in another word, tea should be of high quality, drinkers should be of the same ideals and thoughts, scene should be beautiful and artistic, and the display of objects should be elegant and graceful, hence the marvelous atmosphere of tea tasting.

Similarly, it is a romantic for people to drink coffee and look at the bustling crowd in the coffee shop. Chinese have a special feeling to tea house, but this kind of feeling is weaker than Frenchmen's. (Wu Xiwen, 1997, p.62) ${ }^{[2]}$ The French are inclined to depend on coffee house. Let's say a Petty Bourgeoisie and expression of fashionable life in China. However, in France, drinking coffee is definitely considered as an activity for all of people. In Paris, a lot of streets are covered by a variety of coffee shops which are signs of French's daily life. If they want to drink a cup of coffee, they can enjoy a cup of coffee have a rest, study and make 
friends in cafe at any leisure time if they want. So the French are in and out of these cafes. It seems that their life will come to an end if French live without coffee and coffee bars. That is the life style of French, the romantic heart of French, the nature of French, so they never change the habit of drinking coffee.

\subsection{The Relationship with National Historical Culture}

Chinese tea culture has a history of five thousand years. All people can recognize the fact that tea culture is profound because of national thoughts which combine the essence of Confucianism, Taoism and Buddhism's philosophy. So it is closely related to the Confucian gentle ceremony, the Buddhist pleasant cultivation, Taoist charming idleness in the atmosphere of the tea-something. Tea ceremony should be taken in an elegant and quiet environment, pavilion and loft, around pines bamboos in tea rooms and the small yard, in which people can feel intoxicated.

Through the process of tea sipping and appreciation of tea arts, people can enjoy the wonderful artistic atmosphere in their life, so that they can go into the state of self-cultivation, open-mind, and then achieve physical fitness, purification of the mind and get rid of diseases which would hurt them. Some scholars said the tea ceremony is the core of oriental culture, the essence of humanism, the treasure of all mankind which comes from the contribution of ancient Chinese civilization.

The industry of coffee not only promotes the French economy, but also relates to French culture for centuries. Since the 17th century, in France, especially in the upper class society, there are many coffee arts Sharon because of coffee; in the 18th century of Enlightenment Age, appears to a variety of Sharon, clubs and cafes. LE PROCOPE cafe can be considered as the first coffee shop in Paris. Thinkers like Voltaire, Rousseau and Diderot are frequent customers for LE PROCOPE. Several works of Voltaire and Diderot's world first encyclopedia are completed here; literary giants like Hugo, Balzac, George Sang, Zola created a literary journal in the name of "LE PROCOPE". Cafe in Montmartre College was a sign of the times the University of Paris in the 19th century. There were many artists who lived there for a long time and established the world's sacred sites and spiritual home for writers and artists. In the early 20th century, it has been in the situation of an unprecedented prosperity that Picasso, Hemingway, Van Gogh, Freud, etc. were trying to make their dream come true and enjoy their youthful life.

French coffee has a great relationship with its own culture, as the close relationship between tea and Chinese culture. The unique cuisine culture can not be formed if there is no nation. At the same time, the nations will gain the inner beauty because of the excellent culture.

\subsection{Relationship with the Religion}

The Christianity in Western as important as the Chan Buddhism in China, so we should pay much attention to the Chan Buddhism in tea culture and the spirit of Christianity in coffee culture.

The connection between tea and the Chan Buddhism, after all, should attribute to curative function of tea. We know that monks would doze when sitting in meditation, and drinking tea could refresh them. In the strong trend of tea-adoring in the society, especially in the Tang dynasty, monks' tea drinking also had profound cultural meanings. There were Buddhist allegorical implications in drinking tea, and tea-drinking and Buddhist meditation went along with each other. In order words, tea-drinking and Buddhist meditation were alike in making 
people behave properly to cultivate oneself.

The connection between tea and the thoughts of Chan Buddhism had both the inner and outer reasons: tea was the traditional drink long used in monasteries; and it was the most popular drink in the daily life in monasteries, and the monks had a kind of warm feeling towards tea, and such feeling was connected with life; the refreshing function of tea made it the best assistant for the monks to sit in meditation. Tea's aspiration of life and its lofty characteristics implied or disclosed Buddhist meditation, and expressed the wonderland of it. Therefore, there was theory of "tea resembling Buddhist meditation."

Tea resembling Buddhist meditation presented the high degree of harmony of the thoughts of tea ceremony and Chan Buddhism. (Roberti Roberta, 2001, p.5) ${ }^{[7]}$ Tea functions in Buddhism firstly to be served to gusts, and then a whole set of sober and solemn tea ceremony was set up, at last it becomes an indispensable part in the Chan Buddhism. The underlying reason of its development lay in the uniformity of ideas and thoughts, i.e. the nature of tea went in harmony with Buddhist meditation and realization.

This is a story handed down by Christians. A shepherd called Kaldi in Kaffa of Ethiopia North Africa went out with his sheep one day. He suddenly found that the hordes of sheep become very excited and jump up and down. He takes a close look at them and finds that they are eating a kind of red fruits. He thought it is the fruit that makes sheep become very excited, so he went to a nearby monastery with a red fruit to ask for advice from a priest. After his words, the priest ate the red fruits with curiosity. After a while, the priest became very excited too. Since then, all priests would eat some red fruits before doing mass which later named as Kaffa fruit. Kaffa fruit is the origin of coffee which is popular today.

As we all know, the Western civilization came from the ancient Middle East, Greece and Rome and its basic framework included: religious and secular consciousness. Westerners think God values the individual soul, conflict between the body and soul, man and nature. Under the influence of this concept, the Westerners have a strong sense of personal fighting and competition. Dante believes that family will not exist without individual's participation. The family's glory and nobility rely on person's efforts. The acceptance of human values and human dignity first is each person's waking of self-consciousness and the self-nature's exact affirmation and development by their own free mind. To the Westerners, life is like coffee. If we lost the original freshness of the things we should do it in a new and adventurous way. It is just like coffee, once we brew it, it will lose its original flavor. And then we give it up and find a new one to brew again.

\section{Differences in Character between Chinese and Westerners}

From the comparison of tea culture and coffee culture, we can learn something about their people's characteristics.

\subsection{Different Attitude toward Life}

General characteristics of Western coffee culture are passionate, unrestrained free, simple and convenient. (Diaz Alejandro J, 1999, p.38) ${ }^{[5]}$ Romantic French cafe culture symbolizes elegant charm, romantic ambience, and the pleasant. There are other aspects about coffee culture that we cannot ignore-traditional and unique characters. Coffee for them is not just a kind of drink; it implies a rich cultural meaning. The cafes covered all the urban and rural areas which represent their life style. The French do not pay too much attention to the taste of the coffee, but the environment and mood which they are willing to spend a much higher prize for a small cup of coffee instead of buying a pot of coffee in the busy market. They sip it 
slowly, read books and newspapers, and talk here and there, in all, even to "bubble" for a whole day. People can enjoy coffee in America anywhere and anytime. When Americans drink coffee, it seems that they are engaged in a game without rules. They never pay much attention to the aspects of brewing coffee in Europe. Americans drink coffee in a free way and it is an important part of their lives. Americans are almost a day with coffee. So the United States is the largest country in coffee consumption in the world. In general, American life is a little busy and stressful, so they often prepare a large pot of electric filter coffee, and drink coffee from morning to evening. The taste of this kind of coffee is weak because there is more water and less coffee in it. Therefore, many people criticized that the American coffee is not very delicious. The United States is the largest instant coffee export country, but the United States themselves who do not drink instant coffee so much.

\subsection{Different Approaches to Handling Affairs}

Chinese culture stresses the rules, rigid closed, pay attention to the things spoken and written, to the neglect of real change, like the stability of old-fashioned. Western culture is the actual weight utilitarian culture, not to be rigid, so the ideal thing, like innovation. Western countries do not speak on the principles of social issues, but the element of technology is very strict.

In the long river of history with thousands of years, the Chinese people tend to holistic thinking, emotional thinking and reality, subject and object-oriented integration, emphasis on social, groups, the role of the individual constraints, and gradually formed a Chinese cultural center, and brought together national unity of the national culture, descendants, descendants of the dragon that is sufficient to constitute the pride of the Chinese character and the collective spirit of the character. Western culture is the role of prominent individuals and subjective to the individual as the center, the main object of clear boundaries, respect individual's personality, values, dignity, promote self-centered, individualized concept of self-freedom of movement. The individualism is considered as the core value of Western culture. He "individualism" than the laws of nature for survival of the fittest individuals only through their own efforts, play to their potential ability to protect their own interests in order in the society. Therefore, in this sense the values of a competitive, driven, all focus on self-reliance; self-struggle, the people advocating free enterprise as a code of conduct, to form a deep-rooted in the pursuit of individual national character.

\subsection{Different Character}

Chinese people are very subtle, while the western people are very outward. Chinese people prefer thinking in images, focusing on experience, good through perception and experience, from the relationship between things and grasp the relationship between cognitive object. Use Analogies association, analogy method, Yiyu representative, put the proposal on the metaphor of the interpretation of ideas, perseverance, rotten wood does not discount the skill to be enhanced to euphemistic language, induced with elaborate their views, not only to take care of communication between the object position and psychological, save face, but also make each other nickname his attitude quickly. Westerners tend to abstract thinking, good use of concepts, judgments, and reasoning logical analysis of the object of knowledge, with people attach importance to the expression, emphasizing the language of logical and clear thinking, simple and clear, feeling full, relying on an instance of the viewers. Attitude to democracy and equality, so that interactive communication, focusing on its own insights, virtues impress each other, the pure, bright and clean style as a means of communication. 


\section{Conclusions}

With the development of the global economic integration, the world culture is gradually converging to each other. French coffee culture is spreading widely throughout the world, people consider coffee as a mark of fashion; tea, as a synonym, of old fashion seems to be the elderly and the hermit's "patent", and such a change can be attributed to coffee itself and the charm of French culture. However, since January the 1st, 2008, the French put the smoking ban into practice in public places. It indicates that the phenomenon which people are used to smoking while drinking coffee will never be seen. It will hit the long-standing cafe culture of France.

Similarly, after the tea was spread to Europe, it immediately attracts French people. In the way of advertising and drinking for several times, it was gradually spread to the community. At the same time, it became an integral part of daily life and social activities. The French favorite drink is black tea, green tea and scented tea. In recent years, particularly among French, young people drinking tea has become a fashionable way. Even the romantic French people like to have tea bath which has a function of skin care and losing weight. The multiple effects of tea-drinking, without any side effects, determine its great development space in future.

According to the comparison, the author makes readers know more about Chinese tea culture and Western coffee culture. With the participation of men of letters and scholar-officials in tea tasting, tea also began to highly incorporate the soul of the Chinese traditional culture, especially absorbing the essence of the Confucianism, Buddhism and Taoism, which formed the profound tea ceremony thoughts with Chinese characteristics. According to the origin of coffee, the coffee culture connected with the spirit of Christianity. Today, tea culture and coffee culture are prevalent all over the world, which demonstrates the profundity of Chinese tea culture and Western coffee culture.

Although we drink tea or coffee every day, most of us still know a little knowledge of tea culture and coffee culture. Though this essay, more knowledge of tea culture and coffee culture can be known: the characteristics of Chinese tea and Western coffee, the relationship between tea and coffee and their own national history culture, their spirits in religion and the trend of development.

\section{Acknowledgements}

I would like to acknowledge and extend my sincere gratitude to my beloved family and my colleagues, and without their work, the completion of the paper would not have been possible.

\section{References}

[1] Chen Zhongmao. Zhongguo Chaye Dacidian[M]. Beijing: China Light Industry Press, 2008.

[2] Wu Xiwen. Xiangchun Coffee[M]. Shenyang: Liaoning Science and Technology Press, 1997.

[3] Zheng Wanchun. The history of Coffee [M].Harbin: Harbin Press, 2006.

[4] Black, H.S. Tea culture in France. Pennsylvania: Journal of the Franklin Institute, 1983.

[5] Diaz, Alejandro J. Coffee \& Culture. Farmington Hills: Hispanic, 1999.

[6] Iain, P. Murray. Coffee Culture, Destinations, and Tourism. London: Annals of Tourism Research, 2011.

[7] Roberti, Roberta. Tea Culture. Connecticut: Link-Up, 2001.

[8] Samovar, Larry A, Richard E. Porter and Edwin R. McDaniel. Communication between Cultures. Beijing: Teaching and Research Press, 2000.

[9] Wu Dingbo and Patrick, D. Murphy. Handbook of Chinese Popular Culture. Westport: Greenwood Press, 1994.

[10] Zell, Doug. American Coffee Culture. Taiwan: Fresh Cup, 2001. 